\title{
The amplifier effect: how Pin1 empowers mutant p53
}

\author{
Hai Hu and Gerburg M Wulf*
}

\begin{abstract}
Mutation of p53 occurs in 15 to $20 \%$ of all breast cancers, and with higher frequency in estrogenreceptor negative and high-grade tumors. Certain p53 mutations contribute to malignant transformation not only through loss of wild-type p53 but also through a gain of function of specific p53 mutations. How these hotspot mutations turn p53 from a tumor suppressor into an oncogene had until now remained incompletely understood. In an elegant paper published in the July 12 issue of Cancer Cell, Girardini and colleagues show how Pin1-mediated prolyl isomerization, a regulatory mechanism intended by evolution to support p53's function as a guardian of the genome, can go haywire and accelerate malignant transformation when p53 carries a dominant-negative mutation.
\end{abstract}

For over 20 years p53 has been recognized as a tumor suppressor [1] that induces cell cycle arrest to allow for DNA damage repair or apoptosis of an irreparable cell. Germline mutations of p53 result in the clinical Li Fraumeni syndrome, characterized by high susceptibility to breast cancer, acute leukemias, sarcomas, brain tumors and adrenal cortical carcinoma [2]. Li Fraumeni syndrome is rare, but somatic $\mathrm{p} 53$ mutations occur with a frequency of 15 to $20 \%$ in all breast cancers, and with higher frequency in tumors that carry a poor prognosis, such as high-grade and estrogen receptor-negative tumors [3].

While several hundred cancer-associated p53 mutations have been identified, the general pattern is that p53 in cancer frequently carries missense mutations that allow for the expression of a mutant protein with defective DNA binding but an intact trans-activating domain. This observation has led to the hypothesis that

*Correspondence: gwulf@bidmc.harvard.edu

Beth Israel Deaconess Medical Center, Harvard Medical School, 330 Brookline Ave, Boston, MA 02215, USA mutant p53 confers an advantage to cancer cell growth through a gain of function where the mutant protein is now targeted to DNA sites that encode a cancerpromoting transcriptional program rather than a tumor suppressor program [4]. The recent study by Girardini and colleagues [5] sheds light on the mechanism by which a mono-allelic missense mutation of p53 can turn an indispensable tumor suppressor into a potent oncogene aided by the prolyl isomerase Pin1.

Pin1 catalyzes conformational changes in a subset of mitotic phosphoproteins; via its WW domain, Pin1 will first dock at the phosphorylated serine or threonine, and then Pin1's prolyl isomerase domain will catalyze the 'switch' of the adjacent proline residue from the cis to trans position relative to the protein's carbon backbone [6]. This conformational re-positioning of proline's bulky 5 -carbonyl ring does not change the atomic composition of the target protein, but rather its three-dimensional structure. Thus, the prolyl isomerase Pin1 adds an additional layer of complexity to mitotic signaling networks by regulating post-phosphorylational folding mechanisms that modulate the tertiary structure of a target protein. The simple Pin1 binding motif, pSer/ThrPro [7], is often found multiple times in a given protein, and thus Pin 1 activates a broad range of phosphoproteins involved in cell division. The evolutionary intent of Pin1mediated prolyl isomerization appears to be the coordination of pro-proliferative signals and cell cycle checkpoint regulators to ensure orderly progression through mitosis [8]. This balancing function explains why Pin1 targets include proteins that facilitate cell cycle progression, such as cyclinD1 [9], as well as proteins that can halt mitosis, such as wild-type p53 [10-12]. Because of its simplicity, however, this mechanism is also blind to mutations in the target protein outside the Pin 1 recognition site, and, as Girardini and colleagues discovered, enables mutant p53 to subvert this powerful mechanism to enhance tumorigenesis.

Comparing tumor phenotypes in a mouse model of $\mathrm{Li}$ Fraumeni syndrome (p53 R172H mutation [13]) and the p53 null background, the authors found that it is the presence of the mutant $\mathrm{p} 53$, and not the absence of wildtype $\mathrm{p} 53$, that promotes carcinogenesis, and that mutant 
p53-mediated carcinogenesis is accelerated in the presence of Pin1. The argument that Pin 1 promotes the gain of function of mutant p53 is further strengthened by the fact that Pin1 enhanced carcinogenesis when only a mono-allelic p53 mutation was present - that is, when wild-type and mutant p53 were expressed concomitantly, a situation frequently found in human cancers. In vitro the investigators demonstrate that all the components typical of Pin1-catalyzed prolyl isomerization have to be present for this epistatic relationship between Pin1 and mutant p53: phosphorylation on S/P motifs (S46 and S315) in p53 and the phospho-residue binding WW domain and the enzymatic PPIase domain in Pin1 were required. Functionally, prolyl isomerization of mutant but not wild-type p53 rendered p63 dysfunctional and set off an entirely new transcriptional program that promoted transformation.

Increased Pin 1 expression had previously been observed in breast cancer. These studies had shown that high levels of Pin1 tipped the balance between proproliferative signaling and cell cycle checkpoint control towards uncontrolled proliferation by affecting, for example, expression of cyclin D1 [9], beta-catenin [14], Her2-neu [15] and many other molecules (reviewed in [16]). The novel finding by Girardini and colleagues is that Pin1-catalyzed prolyl isomerization of mutant p53 causes a profound qualitative change in an epithelial cell's transcriptional program that could potentially not only accelerate but also cause cancer.

One of the striking observations was that Pin1 appeared to be dispensable for mutant p53-associated sarcomas and hematological malignancies, while it was absolutely required for the emergence of epithelial cancers, which in the case of Li Fraumeni syndrome are most frequently breast cancers. Not surprisingly, the authors find that cooperation of mutant p53 with Pin1 affects breast cancer outcomes and that the combination of high Pin1 levels and p53 mutation is a predictor of poor prognosis in breast cancer patients.

These findings have important clinical implications; if feasible, inhibition of Pin1 might be an effective way of targeting multiple tumor-promoting genes in breast cancer, including a potential reversion of the detrimental transcriptional program induced by mutant $\mathrm{p} 53$. In $\mathrm{p} 53-$ proficient cancers, on the other hand, Pin1 inhibition might increase genomic instability by hampering its interaction with p63. Hence, knowing the p53 status of a given cancer would be imperative for plans to use Pin1directed inhibition to treat cancer. The conspicuous absence of epithelial tumors in Pin1 null mice that carry mutant p53 raises the question whether epithelial cells have a special requirement for Pin1, which might make epithelial cancers particularly vulnerable to Pin1 inhibition. Finally, Girardini and colleagues' study raises the possibility that there may be more cancer-causing mutations in tumor suppressor genes that use Pin1 to exert a dominant-negative function.

Competing interests

The authors declare that they have no competing interests.

Published: 13 October 2011

\section{References}

1. Baker SJ, Markowitz S, Fearon ER, Willson JK, Vogelstein B: Suppression of human colorectal carcinoma cell growth by wild-type p53. Science 1990, 249:912-915.

2. Li FP, Fraumeni JF Jr: Soft-tissue sarcomas, breast cancer, and other neoplasms. A familial syndrome? Ann Internal Med 1969, 71:747-752.

3. Olivier M, Langerød A, Carrieri P, Bergh J, Klaar S, Eyfjord J, Theillet C, Rodriguez C, Lidereau R, Bièche I, Varley J, Bignon Y, Uhrhammer N, Winqvist R, Jukkola-Vuorinen A, Niederacher D, Kato S, Ishioka C, Hainaut P, BørresenDale AL: The clinical value of somatic TP53 gene mutations in 1,794 patients with breast cancer. Clin Cancer Res 2006, 12:1157-1167.

4. Oren M, Rotter V: Mutant p53 gain-of-function in cancer. Cold Spring Harb Perspect Biol 2010, 2:a001107.

5. Girardini JE, Napoli M, Piazza S, Rustighi A, Marotta C, Radaelli E, Capaci V, Jordan L, Quinlan P, Thompson A, Mano M, Rosato A, CrookT, Scanziani E, Means AR, Lozano G, Schneider C, Del Sal G: A Pin1/mutant p53 axis promotes aggressiveness in breast cancer. Cancer Cell 2011, 20:79-91.

6. Lee TH, Pastorino L, Lu KP: Peptidyl-prolyl cis-trans isomerase Pin 1 in ageing, cancer and Alzheimer disease. Expert Rev Mol Med 2011, 13:e21.

7. Lu PJ, Zhou XZ, Shen M, Lu KP: Function of WW domains as phosphoserineor phosphothreonine-binding modules. Science 1999, 283:1325-1328.

8. Wulf G, Finn G, Suizu F, Lu KP: Phosphorylation-specific prolyl isomerization: is there an underlying theme? Nat Cell Biol 2005, 7:435-441.

9. Wulf GM, Ryo A, Wulf GG, Lee SW, Niu T, Petkova V, Lu KP: Pin1 is overexpressed in breast cancer and cooperates with Ras signaling in increasing the transcriptional activity of c-Jun towards cyclin D1. EMBO J 2001, 20:3459-3472.

10. Wulf GM, Liou YC, Ryo A, Lee SW, Lu KP: Role of Pin1 in the regulation of p53 stability and p21 transactivation, and cell cycle checkpoints in response to DNA damage. J Biol Chem 2002, 277:47976-47979.

11. Zacchi P, Gostissa M, Uchida T, Salvagno C, Avolio F, Volinia S, Ronai Z, Blandino G, Schneider C, Del Sal G: The prolyl isomerase Pin1 reveals a mechanism to control p53 functions after genotoxic insults. Nature 2002, 419:853-857.

12. Zheng H, You H, Zhou XZ, Murray SA, Uchida T, Wulf G, Gu L, Tang X, Lu KP, Xiao ZX: The prolyl isomerase Pin 1 is a regulator of $\mathrm{p} 53$ in genotoxic response. Nature 2002, 419:849-853.

13. Lang GA, Iwakuma T, Suh YA, Liu G, Rao VA, Parant JM, Valentin-Vega YA, Terzian T, Caldwell LC, Strong LC, El-Naggar AK, Lozano G: Gain of function of a 553 hot spot mutation in a mouse model of Li-Fraumeni syndrome. Cell 2004, 119:861-872

14. Ryo A, Nakamura M, Wulf G, Liou YC, Lu KP: Pin1 regulates turnover and subcellular localization of beta-catenin by inhibiting its interaction with APC. Nat Cell Biol 2001, 3:793-801.

15. Lam PB, Burga LN, Wu BP, Hofstatter EW, Lu KP, Wulf GM: Prolyl isomerase Pin 1 is highly expressed in Her2-positive breast cancer and regulates erbB2 protein stability. Mol Cancer 2008, 7:91.

16. Finn G, Lu KP: Phosphorylation-specific prolyl isomerase Pin1 as a new diagnostic and therapeutic target for cancer. Curr Cancer Drug Targets 2008, 8:223-229.

doi:10.1186/bcr2941

Cite this article as: Hu H, Wulf GM: The amplifier effect: how Pin1 empowers mutant p53. Breast Cancer Research 2011, 13:315. 